\title{
DIFFICULTIES IN ENGLISH LANGUAGE LEARNING FOR STUDENTS WITH DYSLEXIA
}

\author{
Alma Lama \\ PhD candidate in English Language Teaching \\ South East European University, Tetovo, North Macedonia, \\ al21449@seeu.edu.mk
}

DOI: 10.2478/seeur-2019-0011

\begin{abstract}
Teachers always try to give their best to educate all students that have been entrusted to them!

Knowing that everybody has the right to learn and be well educated, the Ministry of Education, Science, and Technology after the war took considerable actions in an effort to promote inclusive education in the Kosovo education system (Ministry of Education, Science, and Technology, 2007). However, teachers are facing different challenges while trying to teach students with mild or moderate specific learning difficulties together with those who don't have learning difficulties.
\end{abstract}


Understanding specific learning difficulties may not be hard but handling it is a great challenge.

So what are specific learning difficulties?

This research studies specific areas of inclusive education based on the difficulties students have while learning English Language, how to deal with these difficulties, how can inclusive practices within the school help , what practical teaching approaches can be used, what teaching methods are used or can be used in the inclusive classes in order to come to a conclusion of what can be done more about inclusiveness and understand the importance of inclusive education not only in the centers where the work is done but throughout Kosovo.

Remember: Students with specific learning difficulties are just like you and me, they just have a different learning style!

Keywords: specific learning difficulties, teaching methods, teaching strategies

\section{Specific learning Difficulties (SpLDs)}

According to Arkell, (Helen Arkell Dyslexia Center, 2018)the term 'Specific Learning Difficulties' (SpLDs) is a term that alludes to a distinction or challenges that students face in learning. According to the researchers, students with specific learning difficulties or special educational needs refer to students who need extra help as they find it harder to learn parallel with their peers while students with special needs 
refer to a group of students who have a physical or mental impairment that effect on their ability to carry out normal day to day activities. So, understanding the definition of the term is very important to be addressed during training.

British Dyslexia Association about Specific Learning Difficulties, (British Dyslexia Association, 2012) states that they influence the way in which data is found out and processed. They say that SpLDs are neurological, not psychological and they run in families and take place without any regard of intelligence. They can have a critical effect on education and learning and on the securing of learning proficiency.

As indicated by British Dyslexia Association, ( British Dyslexia Association , 2012), SpLDs as a concept is an umbrella term used to cover a scope of learning challenges, more generally heard as:

- Dyslexia - is a common learning difficulty which exists all over the world and mostly it affects the reading skills.

- Dysgraphia - is a learning difficulty which affects writing and spelling

- Dyspraxia is a learning difficulty involves barriers in physical coordination that shows reflects on lower performance than expected in daily activities for the student's age.

- Dyscalculia - is a learning difficulty associated with hindrance in arithmetical calculations

- Autistic Spectrum Disorder a difficulty in social interaction and communication

- Attention Deficit Hyperactivity Disorders - a disorder that shows an inability to maintain attention and focus, remain on task, wait appropriately, organize materials etc 
- Speech-Language Difficulties is a learning difficulty that makes it hard for students to find the right word when speaking.

Specific Learning Difficulties make the students stay behind in school and a result they lack on learning enthusiasm, lose the motivation, are discouraged and show low academic quality achievement.

Researchers do not know exactly what are the causes of learning difficulties, but they assume that sometimes, factors that affect a developing fetus could be indicated by poor nutrition and exposure to toxins, for example, water paint, detergent, hair coloring etc.

These difficulties can be due to different factors but if a student is not progressing the same as the majority of the class than you may want to consider a possibility of cognitive differences which is related to dyslexia.

According to Decoding Dyslexia Oregon association (Decoding Dyslexia Oregon, 2018) students with Specific Learning Difficulties can benefit in an inclusive education.

Identifying students with SpLDs without a specialist is not an easy task.

Researchers do not know exactly what are the causes of learning difficulties, but they assume that sometimes, factors that affect a developing fetus could be indicated by poor nutrition and exposure to toxins, for example, water paint, detergent, hair coloring etc.

According to (Eunice Kennedy Shriver National Institute of Child Health and Human, 2018) "difficulties in learning can be also inherited in the family". 
Dyslexia as a common learning issue exists all over the world and studies show that it is a learning disorder which affects the reading, writing, spelling, pronunciation skills and how the brain handles the information they read, hear and see. So, in general students with dyslexia, at first, have trouble reading accurately and fluently. It affects the writing too as it has to do with spelling and pronunciation. In learning English as a second language, students with dyslexia also face a special set of challenges.

Some of the difficulties that students with Dyslexia find in learning English are: they may find difficulties to match letters to sounds and to remember how to spell words, they may see letters moving around while reading, they may have troubles telling left from right. They may need more thinking time to remember the right word as well as memorizing sequences sometimes holding a pencil to write by hand even organizing themselves can be difficult but everyone with Dyslexia is different. When they struggle with the task when other people find it easy, they may feel frustrated, angry or sad. Some students try to hide their difficulties as they are worried about what others might think of them.

However, thinking differently has its own benefits.

Researchers claim that students with dyslexia are excellent in practical work, such as inventing, drawing and making things.

They just might do it in a different way to how others would. Many of them have even become very famous. They have become famous dyslexic inventor, writers, scientist, business people, singers, actors etc. 
In Kosovo children with specific learning difficulties struggle with learning in accessing general knowledge but in English Language Learning, they specifically struggle with developing four essential learning skills such as reading, listening, speaking and writing.

\section{Signs and symptoms}

Primary school students have trouble recognizing whether two words rhyme, struggle with learning new words, struggle recognizing letters and matching them to sounds.

Middle school students have trouble remembering many of the words they've studied.

Make many spelling errors. Frequently have to re-read sentences and passages, read at a lower academic level than how they speak if you ask them to read out loud.

High School Students- often skips over small words when reading aloud. They don't read at the expected grade level, do not prefer writing test but multiple choice questions.

\section{English orthography}

The word 'orthography' refers to the rules for writing a language which is related to spelling and punctuation. English Orthography is an English writing system which refers to the rules of writing the English Language. 
According to (Dyslexia-reading-well, 2018), English language contains 26 letters and these letters are combined to create 44 speech sounds and over 250 ways to spell those sounds.

In order to help students with dyslexia, first of all, we need to see to what orthography spelling system do they have in their native language.

In Kosovo, we have students of different ethnicity and the language of each is transparent, where grapheme corresponds to a phoneme.

Students with dyslexia take much longer to learn how to read or write in English and have a tendency to remember the most important phonemes in different context.

Teaching English Language to students with dyslexia it is considered to be a challenge experience but possible so the very first thing to start with is:

Decoding the text - Decoding is a key skill to apply the sound of the letter in English

Language and it helps to correctly pronounce the words from a written text. Understanding how to sound out words they don't know, and as much as practice occurs, fluent reading appears.

Comprehension of language and reading to gain meaning are the core aspects in learning a foreign language which covers the subjects learned and discusses reading skills and the ability to extract the overall meaning of a text. 


\section{TEACHING STRATEGIES IN INCLUSIVE EDUCATION}

- Use visual, auditory support and apply kinesthetically (movement) and tactile (touch) approaches - these are very important as it helps everyone learn better

- Make sure you use different teaching methods in order to stimulate different parts of the brain

- Use assistive technology and encourage students to use it at home

- Give hand-outs in advance and encourage pre-reading.

- Make sure hand-outs are in large print with a clear font.

- Give them more time to process what they comprehend in order to organize and find the right answer knowing that students with dyslexia are very emotional and get easily frustrated

- If asked by students to record the lecture allow that

- Present material in small chunks so they can comprehend easily.

- Arrange to seat with those who are not dyslexic so they can learn together and build confidence at the same time.

\section{Conclusion \& recommendation}

Since our educational system does not provide a Dyslexia specialist, it is hard to bring the conclusion that dyslexic students are present in our schools, however studies shows that Dyslexia appears all around the world and according to Future Learn (futurelearn.com, 2018), one in ten students is dyslexic, and as of this fact we need a closer research to prove the accuracy of the presence of dyslexia in Kosovo. 
Therefore, inclusive education can be a great approach to respond to these needs. We have to consider that students who have specific learning difficulties, time by time need an individual oriented support as they may need more time to process the information that they receive in the class.

Although the majority of schools are trying the best to establish practices and approaches toward direct, explicit and structured intervention in this direction, yet, students with SpLDs need more practice and interactivity and from this can benefit also students who don't have SpLDs.

Secondly, students with SpLDs need continually to work with their peers so they can reach their capacity, catch up with them, stay encouraged and motivated. On the other side, teachers continually need to be trained and follow new practices so they can transform the traditional teaching style into a modern teaching style where students are the ones who work and perform in the class, make students search for the meaning of the lesson, and this will make them interact with technology and see learning as something that motivates them.

Arkell, (Helen Arkell Dyslexia Center, 2018) about Inclusive Education in Low-Income Countries states that the secret of a successful inclusive education programme is in the training of teachers, so continually this has to be part of a curriculum plan.

Lavery, S., Chambers, D., \& Cain, G. (Chambers, Dianne,Shane Lavery, Glenda Cain, 2017) in their book "Service- Learning Enhancing Inclusive Education" investigate the role of other factors for successful inclusive education which includes the conducive learning environment 
in schools created by teachers in the class, empowerment of parents' involvement and community. When everybody works for one purpose, put efforts on it, everybody will succeed.

In order to integrate this practice and adapt these practices every day within the academic year, MEST (Ministry of Education Science and Technology in Kosovo, 2017) should designate a dyslexia specialist and develop an annual list of teacher training related to dyslexia.

MEST should consider no more than 20 students in the class, more English classes into a students' timetable, such as block classes (total of 90 minutes on one day at least four times a week) and also an assistant teacher for every teacher.

Teacher and the assistant find the time in their schedule to plan and apply that plan in practice so they can provide more efforts toward qualitative engagement of students with SpLDs in inclusive classrooms so all students can succeed to their possible capacity. MEST (Ministry of Education Science and Technology in Kosovo, 2017) should also support an online teaching tool for teacher and assistant to consider maybe during the time when students are off of school.

Regarding this, it is worth to consider the established tutoring system from Dr. Susan Barton for students of different age who struggle with spelling, reading and writing due to their specific learning difficulties. This tutoring system is organized according to levels (ten levels in total) and contains everything that teachers need to guide students toward success. It is considered to be simple to use and applicable for all students who are learning English as a second language and also for teachers. 
Dyslexic people have changed the world! Don't give up on them! They are so special, they just have a different learning style and it is a great challenge for teachers but also interesting experience to find out the way they learn which makes teaching fun.

\section{REFERENCES}

- Arkell H.(2015) Helen Arkell Dyslexia Centre https://www.helenarkell.org.uk/about-dyslexia/what-is-an-spld.php

- British Dyslexia Association, B. (2018). British Dyslexia Association. Retrieved from https://www.bdadyslexia.org.uk/dyslexic/dyslexia-andspecific-difficulties-overview

- Decoding Dyslexia Oregon http://www.decodingdyslexiaor.org/legislation

- Eunice Kennedy Shriver National Institute of Child Health and Human Development,N.(2016). What causes learning disabilities? Retrieved from

- https://www.nichd.nih.gov/health/topics/learning/conditioninfo/causes

- FutureLearn, D. (2018). Free Online Courses. Retrieved from https://www.futurelearn.com

- Dyslexia and Foreign Language Teaching

- Lavery, S., Chambers, D., \& Cain, G. (2017). Service-learning (1st ed., p. https://books.google.al/books?isbn=1787141853). Bingley: Emerald Group Publishing.

- Levinson Medical Center for Learning Disabilities 2016

- http://www.dyslexiaonline.com/basics/famous_dyslexics.html Retrieved 27 August 2018

- Ministry of Education Science and Technology 2017 Kosovo. 